\title{
Structural Dependence of Photogenerated Transformation Products for Aromatic Hydrocarbons Isolated from Petroleum
}

Sydney F. Niles ${ }^{\dagger, \ddagger}$, Martha L. Chacón-Patiño ${ }^{\ddagger}, H_{u a n} C^{\prime} n^{\ddagger}$, Alan G. Marshall ${ }^{*}, \dagger$, Ryan P. Rodgers ${ }^{*},+, \neq$

† Department of Chemistry and Biochemistry, 95 Chieftain Way, Florida State University, Tallahassee, FL 32306. United States

¥Ion Cyclotron Resonance Program, National High Magnetic Field Laboratory, Florida State University, Tallahassee, FL, 32310. United States

Submitted to Energy and Fuels (MS \# ef-2021-xxxx)

14 July, 2021

\section{Supporting Information}

1. Heteroatom compound class distribution for (+) APPI FT-ICR MS analysis of virgin ring fractions

Page S2

2. DBE versus carbon number plots and heteroatom compound class distribution for virgin and $24 \mathrm{~h}$ irradiated saturated hydrocarbons

Page S3

3. Heteroatom compound class distribution for (+) ESI FT-ICR MS analysis of virgin and $24 \mathrm{~h}$ irradiated aromatic ring fractions

Page S4

4. Heteroatom compound class distribution for (-) ESI FT-ICR MS analysis of water-soluble $\mathrm{SO}_{\mathrm{x}}$ and $\mathrm{O}_{\mathrm{x}}$ photoproducts

Page S5 


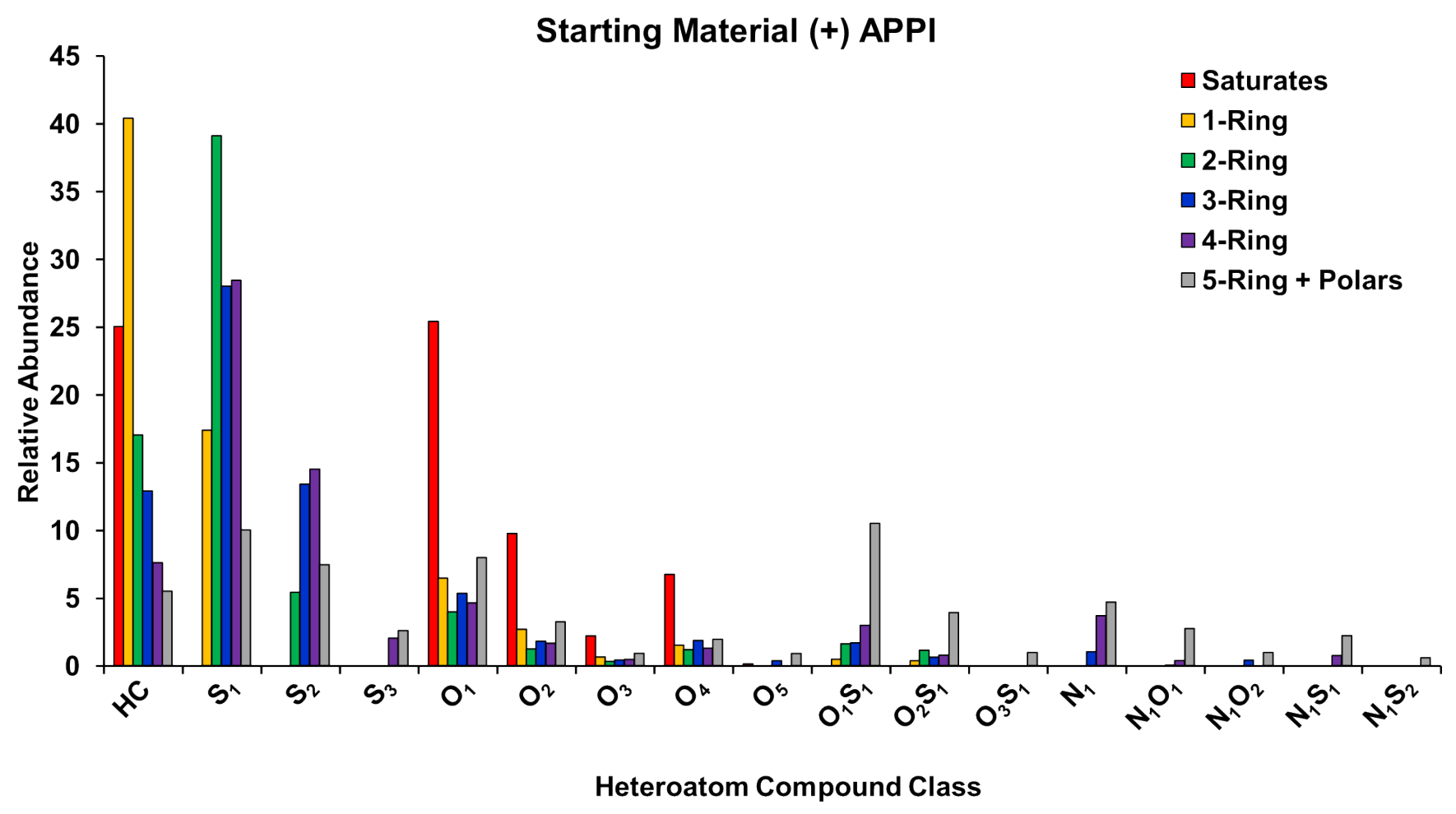

Figure S1: Heteroatom compound class distribution for (+) APPI FT-ICR MS analysis of virgin ring fractions 


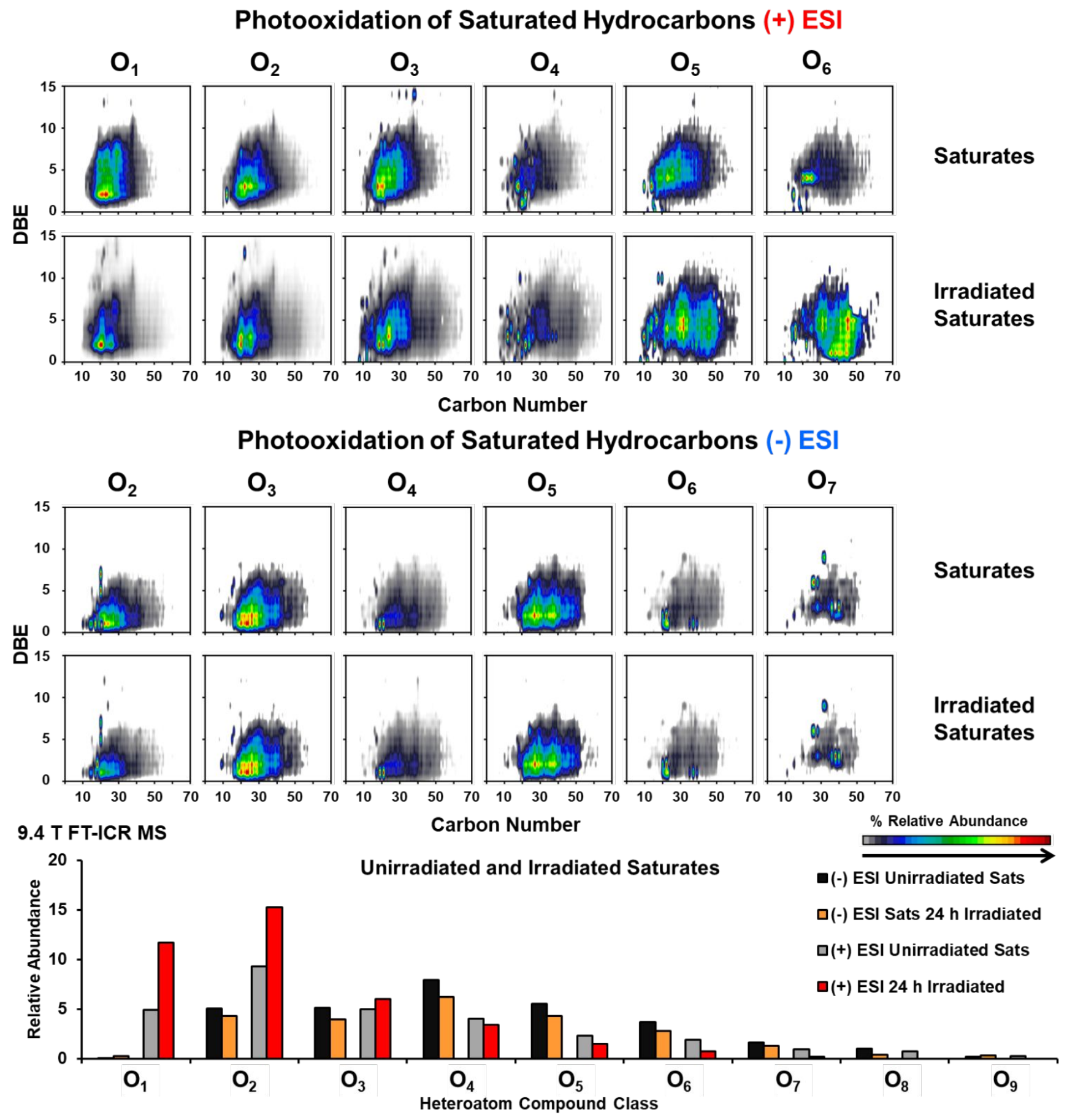

Figure S2: DBE versus carbon number plots (top panel) and heteroatom compound class distribution (bottom panel) for virgin and $24 \mathrm{~h}$ irradiated saturated hydrocarbons analyzed by $(+)$ and (-) ESI FT-ICR MS analysis reveals minimal differences in composition between virgin and irradiated fractions. 

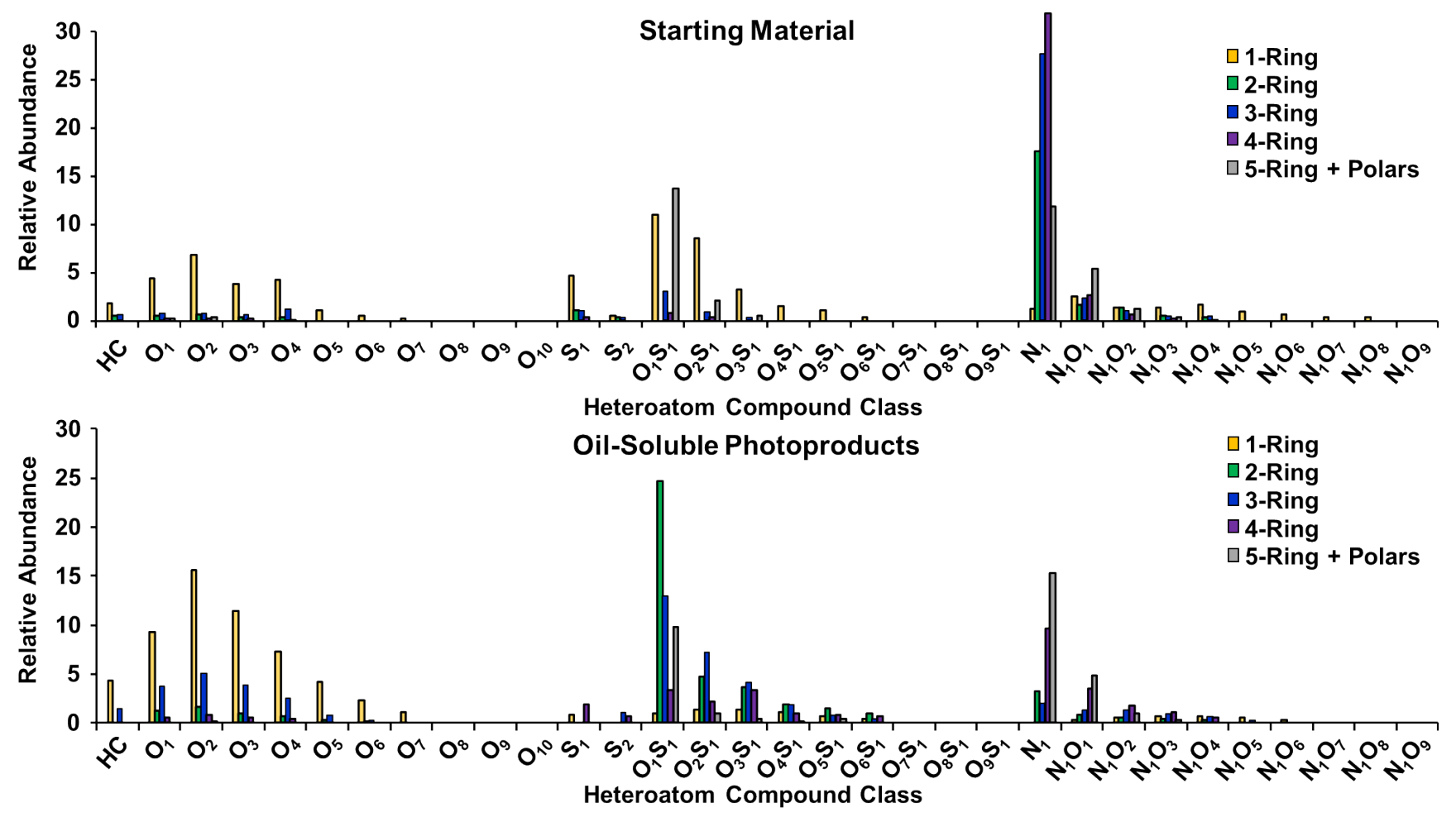

Figure S3: Heteroatom compound class distribution for (+) ESI FT-ICR MS analysis of virgin and $24 \mathrm{~h}$ irradiated aromatic ring fractions 


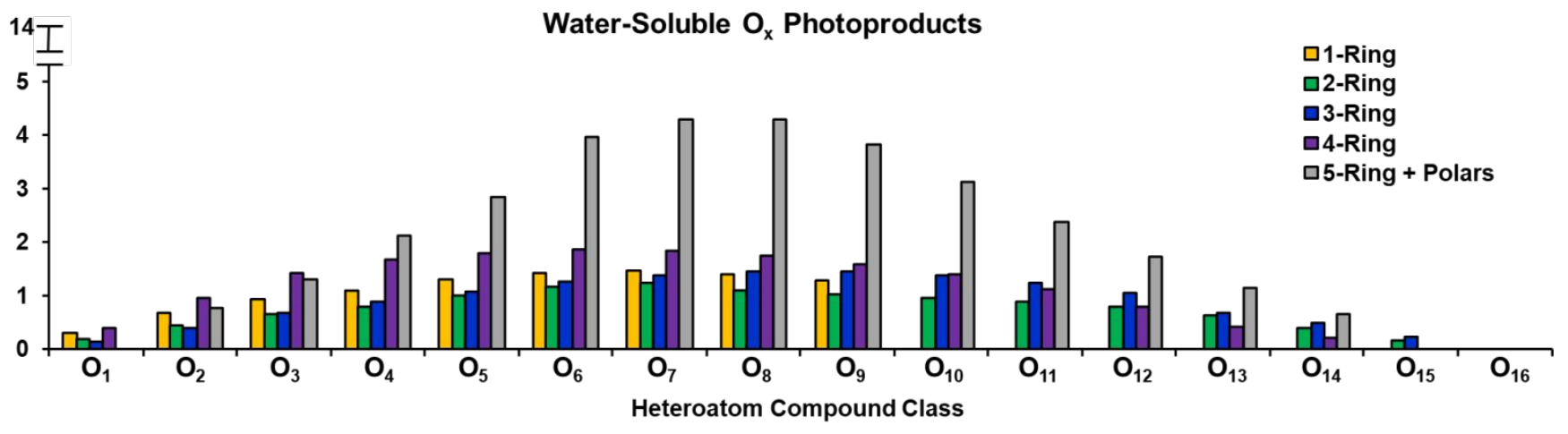

Water-Soluble $\mathrm{O}_{\mathbf{x}} \mathrm{S}_{1}$ Photoproducts

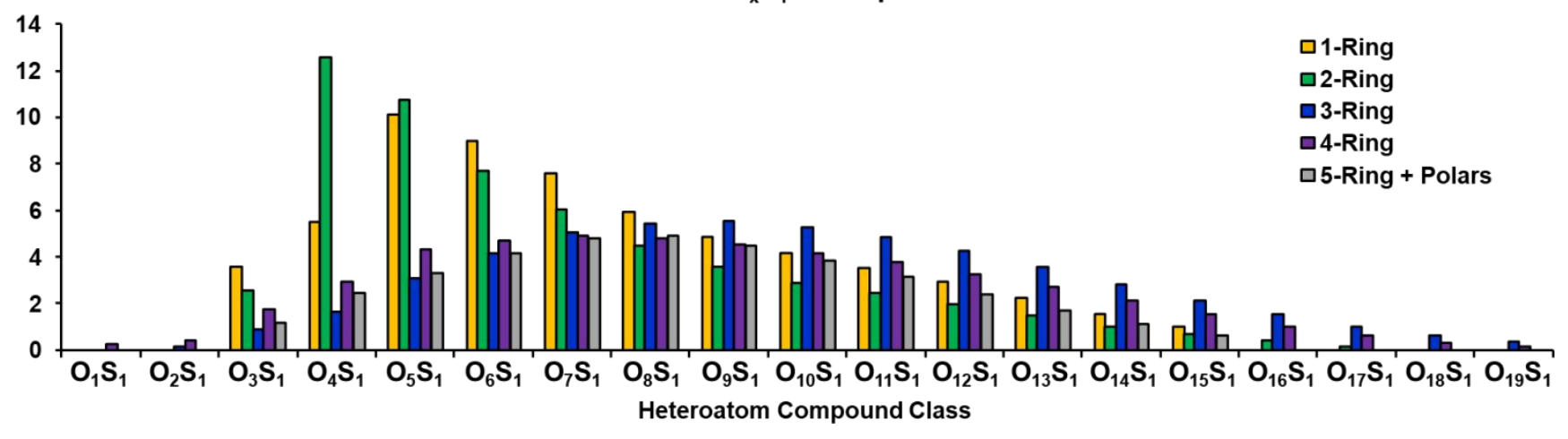

Figure S4: Heteroatom compound class distribution for (-) ESI FT-ICR MS analysis of water-soluble $\mathrm{O}_{\mathrm{x}}$ (top panel) and $\mathrm{SO}_{\mathrm{x}}$ (bottom panel) photoproducts 